\title{
A relação natureza-sociedade no modo de produção capitalista
}

The nature-society relation in the capitalist mode of production Fabiane Agapito Campos de Souza*

Resumo - Marx empreendeu um profundo estudo sobre a sociedade
capitalista; atualmente, porém, a sua contribuição para o entendimento
desta sociedade tem sido questionada devido, principalmente, à
derrocada do socialismo real. Este artigo sustenta a tese de que o
objetivo da obra marxiana foi entender a sociedade capitalista e seu
funcionamento. Mesmo temas tão atuais como a questão ambiental,
objeto principal deste artigo, podem ser debatidos a partir dos fios
condutores do pensamento crítico-dialético. A natureza tem sido alvo
dos mais variados discursos e a sustentabilidade, discussão fomentada
pela ONU, visa dar um norte aos processos sociais para o combate à
devastação ambiental em curso. Entretanto, este trabalho analisará
esse discurso e ainda lançará desafios amparados no autor
mencionado. Palavras-chave: marxismo; sustentabilidade; natureza; capital e trabalho.

\begin{abstract}
Marx undertook a thorough study on capitalist society; however, at present his contribution to understanding this society has been questioned, mainly due the collapse of real socialism. This article supports the theory that the objective of Marx's work was to understand capitalist society and its functioning. Even current topics such as environmental issues, the main object of this article, can be debated through the guidelines of the critical-dialectical thought. Nature has been a target of the most varied speeches. Sustainability, of which the discussion is promoted by the UN, aims to guide the social processes that fight the current environmental devastation. This paper will examine this argument and propose challenges, supported in the mentioned author.
\end{abstract}

Keywords: Marxism; sustainability; nature; capital and labor.

\footnotetext{
* Mestre pelo Programa de Pós-Graduação em Serviço Social da Universidade do Estado do Rio de Janeiro e Assistente Social na Prefeitura de Resende-RJ. Correspondência: Av. Joaquim Magalhães, №180, BL:15 Apto:201 Bairro: Sen. Vasconcelos. Rio de Janeiro-RJ CEP 23012-120. E-mail: <fa.agapito@gmail.com>
} 


\section{Introdução}

Nas últimas décadas, o pensamento marxista tem sido posto à prova em virtude das transformações ocorridas no mundo do trabalho, impondo um desafio àqueles que se utilizam desta teoria para compreender e transformar o mundo contemporâneo.

As críticas a este modelo de explicação centram-se, principalmente, nas alterações ocorridas desde a década de 1970, amparadas no crescimento do setor de serviços, na flexibilização das relações de trabalho, nos processos e automatização da produção e na consequente expulsão do trabalho vivo, dentre outros. Constituindo-se, assim, para alguns pesquisadores, como provas da derrocada do materialismo histórico-dialético enquanto teoria explicativa da realidade.

Contribui também para o aumento das críticas ao marxismo o triunfo do capitalismo frente ao socialismo real, entendido por muitos como prova cabal da insuficiência da teoria marxiana para explicação do funcionamento da sociedade capitalista. Embora esta seja a crítica recorrente, é necessário destacar que Marx dedicou grande parte de seus estudos visando à compreensão crítica do funcionamento do modo de produção capitalista e pouco teorizou sobre o socialismo.

Por último, encontram-se as críticas centradas no objeto de estudo deste artigo, a questão ambiental. Hoje coloca-se em questão se o capitalismo encontrará limites através da mobilização da classe operária, como previu Marx (2011), ou se este, antes disso, será inviabilizado pela finitude dos recursos naturais.

Há alguns anos atrás, ao falar da limitação dos recursos hídricos, dos combustíveis fósseis, da terra produtiva, dentre outros, imaginava-se que o homem conseguiria equacionar estes problemas com o desenvolvimento da ciência. Porém, hoje é notório que o planeta não está conseguindo se recompor com a celeridade com que é destruído, e muito menos os homens estão conseguindo elaborar tecnologias que venham a poupar e/ou retardar o esgotamento dos recursos indispensáveis à nossa sobrevivência. Diante deste dilema, este artigo pretende conectar alguns pontos dessa discussão com a teoria marxiana e extrair dela algumas repostas para este problema hodierno.

\section{O que é natureza?}

Alguns estudiosos afirmam não existir mais uma "natureza natural", haja vista a apropriação dela pela racionalidade humana. Ou seja, com o desenvolvimento da sociedade capitalista, até mesmo as reservas naturais cumprem uma função social dentro desta racionalidade. 
Para Lefebvre o espaço natural, a natureza seria aquilo que escapa à racionalidade e é atingida através do imaginário. Mas o que não escapa à racionalidade hoje? Mesmo as áreas mantidas como reserva de recursos naturais, 'capital natural' não deixam de ser objeto da racionalidade ao se constituírem enquanto tal. (LIMONAD, 2004, p. $1 ; 2)$.

Limonad (2004), dialogando com Lefebvre, questiona o que se entende hoje por espaço natural e chega à conclusão de que cada sociedade elabora seus próprios espaços, atribuindo significações diferenciadas para eles. As práticas sociais informam as representações acerca dos espaços sociais, e quando essas práticas sociais mudam ao longo do tempo, as representações também são alteradas.

Como a sociedade capitalista é uma sociedade dividida por classes sociais antagônicas, é evidente que os discursos e práticas acerca dos espaços também acabem por demonstrar essa cisão. As forças hegemônicas tendem a produzir um discurso pautado na sustentabilidade, ou seja, na preservação dos recursos naturais, de maneira a não inviabilizar a produção capitalista no futuro; já as contra-hegemônicas buscam uma possibilidade de apropriação da natureza enquanto valor de uso, como um modo de garantir a reprodução e sobrevivência da humanidade.

Entretanto, a questão do desenvolvimento sustentável não tem sua eficácia problematizada na medida em que a própria lógica de funcionamento do capitalismo impede sua implementação. Pois trata-se de um sistema socioeconômico baseado na exploração intensa dos meios de produção, tanto da matéria-prima (natureza) quanto do homem (trabalho), uma vez que o consumo desenfreado é a razão de expansão e manutenção de crescimento do próprio sistema. Por mais que o ideário de sustentabilidade esteja em voga nos dias atuais, o que se verifica na prática é o aumento da produção como um todo, bem como da poluição que o acompanha.

\section{O modo de produção capitalista e a articulação entre a sociedade e a natureza}

Historicamente, o ser social se articula com a natureza ao satisfazer as suas necessidades. Mediante este ato, produz a si mesmo através do trabalho, enquanto ser humano genérico. Assim, a dimensão ontológica do ser social interdita qualquer possibilidade de análise da relação sociedadenatureza de forma dicotômica ou dualista.

A intensa atividade humana sobre a natureza gerou incertezas acerca do futuro, levando até mesmo os capitalistas a defenderem a "preservação" do meio ambiente por meio da adoção de práticas "sustentáveis" na produção. Entretanto, faz-se necessário descortinar esse tema sob a perspectiva marxista. 
Marx nunca escreveu especificamente sobre a escassez dos recursos naturais. No entanto, em parte de sua obra é possível vislumbrar essa preocupação, principalmente sobre países europeus e da América do Norte, que já sofriam, em algumas regiões, com a degradação do solo. Logo, a crítica da agricultura capitalista forneceu fios condutores que nos permitem refletir sobre a relação natureza-sociedade na sociedade de produção de mercadorias. Para ele, é impossível pensar o homem dissociado da natureza na medida em que ela é parte integrante da história da humanidade. Assim, encontramos em Marx (2010) o sentido da relação do homem com a natureza.

Praticamente, a universalidade do homem aparece precisamente na universalidade que faz da natureza inteira o seu corpo inorgânico, tanto na medida em que ela é 1) um meio de vida imediato, quanto na medida em que ela é o objeto/matéria e o instrumento de sua atividade vital. A natureza é o corpo inorgânico do homem, a saber, a natureza enquanto ela mesma não é corpo humano. O homem vive[r] da natureza significa: a natureza é o seu corpo, com o qual ele tem de ficar num processo contínuo para não morrer. Que a vida física e mental do homem está interconectada com a natureza não tem outro sentido senão que a natureza está interconectada consigo mesma, pois o homem é uma parte da natureza. (MARX, 2010, p. 84 grifo no original).

O homem é parte integrante da natureza e manifesta uma relação claramente orgânica, dialética e ontológica, que envolve uma simbiose entre os entes. Esta relação é histórica e parte da produção humana dos seus meios de vida. É justamente a partir desta relação que Marx (2010) passa a compreender os desafios da produção no seio da sociedade capitalista. Segundo Foster (2005), é possível extrair das críticas de Marx à agricultura capitalista importantes contribuições ao pensamento ecológico.

Na realidade, a questão da natureza só passou a ser um problema de investigação com o advento da sociedade capitalista e o seu consumo acelerado de matérias-primas. A partir da celeridade imposta pelo sistema produtivo, com o uso da máquina, o problema "natureza" começou a se impor e, nos tempos modernos, passou a ser balizado pelo paradigma da escassez. A pergunta a ser respondida era se o planeta poderia sustentar um modo de produção avassalador, como o nosso, ou se enfrentaríamos a escassez de matéria-prima ou dos recursos naturais indispensáveis para a sobrevivência humana. A questão foi levantada em primeiro lugar por Malthus (apud FOSTER 2005) em relação à população do planeta versus alimentação disponível; tempos depois, a mecanização da agricultura resolveu o problema. Agora, a pergunta se volta a outros recursos naturais, como a água e o petróleo, dentre outros. 
Para Marx (2011), a relação natureza-sociedade está inscrita na produção e reprodução da vida humana, ou seja, o trabalho é a categoria central, uma determinação ontológica fundamental da humanidade.

Antes de tudo, o trabalho é um processo de que participam o homem e a natureza, processo em que o ser humano, com sua própria ação, impressiona, regula e controla seu intercâmbio material com a natureza. Defronta-se com a natureza como uma de suas forças. Põe em movimento as forças naturais de seu corpo - braços e pernas, cabeças e mãos -, a fim de apropriar-se dos recursos da natureza, imprimindo-Ihes forma útil à vida humana. Atuando assim sobre a natureza externa e modificando-a, ao mesmo tempo modifica sua própria natureza. (MARX, 2011, p. 211).

O trabalho, portanto, só ocorre sob um duplo aspecto: o homem trabalha e, enquanto isso, transforma-se a si mesmo; atuando sobre a natureza externa, muda ao mesmo tempo sua própria natureza. Por outro lado, a natureza também termina por transformar-se em meios, em objetos de trabalho e em matérias-primas. A atividade produtiva é o mediador da relação sujeito e objeto, homem e natureza.

O vínculo do homem com a natureza é um vínculo dialético, pois envolve uma unidade profunda entre eles. Este laço que os une se fortalece através da invenção técnica, do conhecimento que cada vez mais domina a natureza em benefício do homem. O mundo humano só é possível com a junção do homem e da natureza; a partir da atividade do primeiro, é possível dar forma a objetos, fruto das mãos e do pensamento do ente criador que necessita de tais coisas para a satisfação de suas necessidades.

O trabalho é uma necessidade, uma vez que o homem não consegue desenvolver-se sem a mediação com a natureza. E, neste sentido, as necessidades alteram-se porque o trabalho vai criando novos produtos enquanto novas necessidades são forjadas, levando o homem a uma busca incessante para satisfazê-las. Por isso, é possível afirmar que o trabalho "chega a ser 'contra a natureza' em dois sentidos: enquanto labor, existe esforço e disciplina, modifica a natureza em torno do homem e dentro do homem." (LEFEBVRE, 1979, p. 32).

O homem modifica a natureza através do processo de trabalho, constituído por três elementos fundamentais: o ato do trabalho em si, seu objeto (matéria-prima) e os meios utilizados na modificação deste objeto. Marx (1996) destaca essa organicidade entre o homem e os elementos da natureza enquanto objeto e meios de trabalho.

Portanto, é possível estabelecer, a priori, que os objetos de trabalho encontram-se disponíveis na natureza e somente a partir do trabalho é possível desconectá-los da terra. É importante salientar que, se um objeto é filtrado, por assim dizer, através de um trabalho prévio, recebe a denominação de matéria-prima. "Por exemplo, o minério já arrancado que agora 
vai ser lavado. Toda matéria-prima é objeto de trabalho, mas nem todo objeto de trabalho é matéria-prima." (MARX, 1996, p. 298). Já o meio de trabalho expressa-se em objetos com propriedades mecânicas, físicas e químicas, que se interpõem entre o homem e a matéria-prima para auxiliar na atividade de dar uma forma útil a ela, transformando-a em um valor de uso. Este irá completar determinada necessidade ou se tornará matéria-prima em outros ramos de atividade. Posto que o objeto e também o meio de trabalho já são produtos, o trabalho é diferenciado por consumir produtos (matéria-prima), transformando-os em novos produtos. Desta forma, o processo de trabalho passa-se entre o homem e a natureza, que supre as necessidades daquele com os objetos de trabalho, bem como os meios de produção.

Neste sentido, ao discutir a questão do processo de trabalho, Marx (1996) busca conectar o homem e a natureza, destacando a relação de ambos para a construção do próprio homem enquanto ser social. O trabalho é distinto de outras atividades humanas por ser o metabolismo entre sociedade e natureza e por pressupor uma interação na própria sociedade. Foi através desta interação entre os homens que surgiu um novo tipo de ser, o ser social.

O conceito de metabolismo em Marx (1996) traz em seu bojo a contradição da falha metabólica, baseada na cisão entre a cidade e o campo e entre os seres humanos e a terra. Primeiro através da apropriação do solo e suas propriedades naturais, por meio de técnicas intensivas na agricultura e na indústria de larga escala, além da apropriação voraz das matérias-primas; segundo, a própria divisão entre campo e cidade, onde grande parte da população terminou por buscar refúgio devido à expulsão do campo. Ou seja, o metabolismo entre o homem e a natureza, na sociedade capitalista, é interrompido, já que grande parte da população permanece alijada do contato com a natureza.

\section{O desenvolvimento das forças produtivas e a escassez dos recursos naturais}

O desenvolvimento das forças produtivas permite explorar os recursos naturais em uma região, descobrir novos usos para determinados recursos e economizar matérias-primas para auferir maiores lucros. Ou seja, a ciência tem realizado um importante papel para o desenvolvimento das forças produtivas.

Esse desenvolvimento coloca em cena o grande problema da escassez e até mesmo esgotamento dos recursos naturais, provocando discursos antagônicos sobre a questão. As forças hegemônicas tendem a produzir um discurso pautado na sustentabilidade, ou seja, na preservação dos recursos naturais, de maneira a não inviabilizar a produção capitalista no fu- 


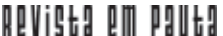

\} A RELAÇÃO NATUREZA-SOCIEDADE NO MODO DE PRODUÇÃO CAPITALISTA - SOUZA, F. A. C. \}

turo; já as contra-hegemônicas buscam uma possibilidade de apropriação da natureza enquanto valor de uso, como um modo de garantir a reprodução e sobrevivência de determinados grupos sociais atrelados culturalmente a estes espaços. Logo, de forma não subordinada à lógica do valor.

Lefebvre (1973) argumenta que o problema do "meio ambiente" é um problema que envolve todo o espaço, tanto a sua produção quanto a sua gestão. Além disso, que o discurso hegemônico tende a ser cindido e mascara um problema global, o da fragmentação do espaço, uma vez que o mesmo adentra o circuito da produção enquanto uma mercadoria que se compra e vende.

[...] A natureza não dota os eco-sistemas duma estabilidade eterna; eles evoluem, restabelecendo-se após a introdução ou a desaparição de um 'factor'. Mas como viver numa destruição perpétua, sem estabilidade relativa? Como viver no laboratório? O problema central é o do espaço e não do 'meio ambiente'. Quando destruído, um ecosistema nã̉o pode ser reconduzido. Basta que um fragmento desapareça para se tornar necessário que todo o pensamento teórico e a prática social empreendam uma recriação da totalidade e essa recriação não pode ser levada a cabo pouco a pouco; terá, portanto, que ser produção de um espaço. (LEFEBVRE, 1973, p. 29).

A natureza, ao se tornar ela mesma mercadoria, desencadeia um problema que atinge todo o espaço, pois este entra na lógica do capital. Desta forma, a questão do desenvolvimento sustentável não tem sua eficácia problematizada na medida em que a própria lógica de funcionamento do capitalismo impede sua implementação. Isto, pois é um sistema socioeconômico baseado na exploração intensa dos meios de produção, tanto da matéria-prima (natureza), quanto do próprio homem (trabalho), uma vez que o consumo produtivo desenfreado é a razão de expansão e manutenção de crescimento do próprio sistema.

O consumo predatório utilizado para o desenvolvimento desse sistema engendra o desaparecimento da natureza, restando apenas fragmentos desta em locais onde a própria geografia impôs dificuldades para a exploração produtiva. Porém, mesmo nos lugares onde a proteção à natureza é pretendida e está regulada, o capital encontra outra forma de capitalizála. Logo, também é importante problematizar a questão da construção de espaços como parques naturais, que entram na órbita do capital enquanto espaço de consumo do lazer.

É possível perceber como, nas cidades, o apelo à produção de "espaços verdes" (LEFEBVRE, 2002) é grande. Ou seja, já que os desmatamentos são "inevitáveis", cada indivíduo é chamado a fazer a sua parte e contribuir para um mundo melhor. O que está por trás desse mecanismo de responsabilização do indivíduo pela preservação da natureza é a lógica liberal, apregoando um consumo de resquícios de "espaço verde" para camuflar a apropriação desses espaços pelo capital. É muito mais propício, 
neste tempo, montar uma estratégia de convencimento individual para a campanha "verde", que associa à ação virtuosa de indivíduos as ideias de responsabilidade individual diante do risco e da crise, já que é "inevitável" a escassez e a destruição iminente.

A natureza é destituída de sua áurea mística dos tempos antigos e passa a demonstrar uma fragilidade, antes desconhecida, perante as promessas iluministas do homem racional e do progresso. Porém, não se pode perder de vista que a própria sobrevivência humana está condicionada à manutenção da natureza em um limite aceitável, que permita ao homem a continuação da sua existência através da preservação de elementos naturais, como a terra e a água, dentre outros. Isso leva a questionamentos sobre a viabilidade da manutenção da vida no planeta, uma vez que os elementos vitais (água e ar) estão sendo destruídos.

Assim, estabelece-se a problemática da questão "natureza" como simulacro. Colocada à venda no "balcão" dos negócios capitalistas e disputada por grandes compradores, é despedaçada e exaurida dos componentes que the dão vida. Os seus fragmentos (uma árvore, uma flor, um animal silvestre, um estilo de vida exótico que resgate elementos bucólicos na cidade) passam a suprir essa necessidade de contato do homem com esse outro.

Diante de tudo o que foi exposto até agora, são pertinentes os seguintes questionamentos: será possível a promoção de um reencontro entre o homem e a natureza no interior das relações sociais capitalistas, no sentido de reintegração da falha metabólica à que alude Marx? Será a sustentabilidade um caminho rumo a esse objetivo? No próximo tópico tentaremos responder a essas indagações.

\section{Sustentabilidade: saída para a crise ambiental?}

Ficou claro até aqui que a preocupação com a questão da natureza remonta há vários séculos atrás, principalmente com o advento do modo de produção capitalista e seu consumo expansivo dos recursos naturais. Porém, a partir de meados do século XX, a preocupação ambiental voltou a ocupar um lugar privilegiado nas discussões acadêmicas - devido a uma grande preocupação teórica com a iminente destruição da natureza - através da divulgação de pesquisas. Estas mostravam a finitude dos recursos indispensáveis à sobrevivência humana no planeta e todos os seus efeitos catastróficos, associados ao aquecimento da Terra, à escassez da água, à desertificação e a outros fenômenos que indicavam a necessidade de se repensar o âmbito da produção até aquele momento.

O grande marco das discussões ambientais aconteceu em 1972, quando a Organização das Nações Unidas (ONU) convocou a Conferência das Nações Unidas sobre o Ambiente Humano, em Estocolmo (Suécia). 


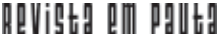

\} A RELAÇÃO NATUREZA-SOCIEDADE NO MODO DE PRODUÇÃO CAPITALISTA - SOUZA, F. A. C. \}

Essa conferência ajudou a fomentar as discussões sobre o tema fora do âmbito acadêmico, fornecendo suporte aos movimentos sociais aglutinados em torno da temática. A partir desta conferência foi criado o Programa das Nações Unidas para o Meio Ambiente.

O conceito de desenvolvimento sustentável passou a fazer parte do vocabulário da ONU a partir de 1987, através da publicação do relatório Nosso futuro comum, que trazia as seguintes assertivas:

O desenvolvimento sustentável é o desenvolvimento que encontra as necessidades atuais sem comprometer a habilidade das futuras gerações de atender suas próprias necessidades.

Muitos de nós vivemos além dos recursos ecológicos, por exemplo, em nossos padrões de consumo de energia... No mínimo, o desenvolvimento sustentável não deve pôr em risco os sistemas naturais que sustentam a vida na Terra: a atmosfera, as águas, os solos e os seres vivos.

Na sua essência, o desenvolvimento sustentável é um processo de mudança no qual a exploração dos recursos, o direcionamento dos investimentos, a orientação do desenvolvimento tecnológico e a mudança institucional estão em harmonia e reforçam o atual e futuro potencial para satisfazer as aspirações e necessidades humanas. (ONU, 2013).

Em outras palavras, a noção de desenvolvimento sustentável foi pautada na conjugação de esforços para a manutenção de um nível aceitável do consumo, com o objetivo de guardar a natureza enquanto um "estoque" para as gerações futuras, de modo a garantir a longevidade da produção e dos seres humanos.

Embora, como já foi visto, a questão da natureza já ocupasse um lugar de destaque no pensamento científico, foi no decorrer dos anos de degradação ambiental que ganhou força o pensamento da sustentabilidade enquanto um marco normativo para a conjugação da ordem econômica e da natural. Sua finalidade era assegurar a sobrevivência humana e o desenvolvimento econômico.

Já ficou provado que o crescimento econômico engendra o aquecimento global do planeta através da produção de gases que propiciam o efeito estufa, a escassez da água, o aumento da desertificação, do desflorestamento, do nível do mar, entre outros processos que indicam a saturação do planeta com o ritmo produtivo capitalista. A crise ambiental é fruto do desequilíbrio entre a produção e a natureza. Esta, incapaz de se regenerar no mesmo ritmo do primeiro, passa a ser alvo de propostas para deter o avanço desse quadro caótico. Uma saída bem difundida é o ideário da sustentabilidade.

Segundo Leff (2006), o discurso do desenvolvimento sustentável busca estabelecer um consenso entre as classes capaz de aglutinar em torno da questão ambiental todos os esforços para salvaguardar o planeta de sua 


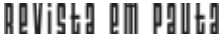

\} A RELAÇÃO NATUREZA-SOCIEDADE NO MODO DE PRODUÇÃO CAPITALISTA - SOUZA, F. A. C. \}

iminente destruição. Trata-se, assim, de um discurso reformista que acredita na capacidade reguladora sobre o sistema capitalista, responsável pela consequente mitigação dos impactos negativos decorrentes do seu desenvolvimento. Porém, o movimento proposto pela ONU, a princípio, ficou restrito a uma retórica ambiental e de pouco alcance na vida prática de empresas e países centrais.

[...] o discurso do desenvolvimento sustentado chegou a afirmar o propósito de tornar sustentável o crescimento econômico através dos mecanismos do mercado, atribuindo valores econômicos e direitos de propriedade aos recursos e serviços ambientais, mas não oferece uma justificação rigorosa sobre a capacidade do sistema econômico para incorporar as condições ecológicas e sociais (sustentabilidade, equidade, justiça, democracia) deste processo de capitalização da natureza. (LEFF, 2006, p. 137).

O autor ressalta que, mesmo com várias conferências promovidas pela ONU em torno do tema, faltou unir o discurso à prática. Em vez disso, a retórica do debate foi ganhando mais espaço, a ponto de ele ser muito difundido e popular, sendo também incorporado pelos segmentos empresariais na busca pela legitimação de modificações propostas, visando a um reordenamento espacial. Neste sentido, Assis (2011) reforça a tese de que atualmente ocorre um reforço na ideia da preocupação ambiental, aliada à exploração capitalista materializada no discurso do desenvolvimento sustentável e capturada pelas empresas em suas justificativas de intervenção no âmbito social, cultural e ambiental na localidade de sua atuação.

A crítica de Leff (2006) ao ideário do desenvolvimento sustentável reside, justamente, no fato de o ambiental estar contido na esfera econômica, na qual a escassez de bens e serviços ainda justifica os excessos perpetrados contra a natureza. O dilema imposto aos sujeitos, visando ao controle racional dos recursos ambientais, não é encampado pelo capital e, com isso, o discurso não se traduz em práticas concretas.

A retórica do desenvolvimento sustentado reconverteu o sentido crítico do conceito de ambiente em um discurso voluntarista, proclamando que as políticas neoliberais hão de nos conduzir para os objetivos do equilíbrio ecológico e da justiça social pela via mais eficaz: a do crescimento econômico guiado pelo livre mercado. (LEFF, 2006, p. 141).

Limonad (2004) também acredita que o conceito de desenvolvimento sustentável incorpora valores capitalistas, uma vez que este tem suas raízes na economia. O termo sustentabilidade evoca significados diversos para diferentes pessoas, mas "é muito difícil ser a favor de práticas 'insustentáveis' assim o termo cola como um reforço positivo de políticas, conferindo-lhes a aura de serem ambientalmente sensíveis." (HARVEY apud 


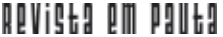

\} A RELAÇÃO NATUREZA-SOCIEDADE NO MODO DE PRODUÇÃO CAPITALISTA - SOUZA, F. A. C. \}

LIMONAD, 2004, p. 5). A autora ainda sustenta que, assim como a natureza, a ideia de sustentabilidade é socialmente criada e integra o corpo de representações hegemônicas do espaço na contemporaneidade. É interessante notar que a ideia de sustentabilidade usualmente tende a ser acompanhada pelo discurso da escassez e é por ele legitimada.

Por mais que o ideário da sustentabilidade esteja em voga nos dias atuais, o que se verifica é o aumento da produção como um todo, bem como da poluição que o acompanha. E mais, a preocupação ambiental foi capturada pela lógica capitalista e transformada em créditos que permitem aos seus detentores continuarem a poluição como sempre o fizeram. Ou seja, os créditos de carbono são adquiridos nas regiões que poluem menos - via de regra, os países periféricos - e repassados às regiões mais desenvolvidas e poluidoras. No entanto, as consequências não se mantêm em determinada região, mas todo o globo terrestre é atingido pelos efeitos da crescente destruição. Neste sentido, Fontes (2010, p. 184) afirma que

Posteriormente, a institucionalização da sustentabilidade favoreceu o estabelecimento de padrões de mensuração internacional, cuja ponta mais visível é a generalização dos créditos de carbono, pelos quais os grandes poluidores compram das regiões menos poluídas a capacidade de continuar sua devastação. Embora envolva na atualidade forte circulação de capitais fictícios, seu ponto de partida é a expropriação efetiva da capacidade humana de subsistir no planeta, que se torna propriedade de alguns através de tais títulos.

Portanto, Leff (2006), Assis (2011), Limonad (2004) e Fontes (2010) fazem uma análise correta do movimento ambiental proposto pela ONU, já que em nenhum momento é proposto pensar a natureza de modo contrário à racionalidade vigente. Apenas propõe-se uma moderação aos ataques do capital contra o ecossistema. Essa astúcia discursiva captura o ambiente e o social, subordinando-os à lógica capitalista, terminando por legitimar a expropriação e dirimindo os conflitos entre as classes. Essa estratégia é funcional ao capital, que pode continuar degradando e apropriandose como bem entender do meio ambiente, transformando os bens naturais (valores de uso) em valores de troca. A racionalidade do lucro permanece e se acentua em tempos neoliberais, nos quais a utopia do desenvolvimento sustentado conserva os pilares econômicos fundamentados na transformação dos bens comuns em propriedade privada.

É claro que a natureza, sob essa lógica, assume a forma de capital, ou melhor, capital natural, em que a valorização do ambiente passa apenas pela questão da "conservação" para a geração futura. Aqueles espaços naturais com reconhecida diversidade biológica e cultural são "capitalizados" e transformados em áreas destinadas ao ecoturismo; com isso, também sofrem degradação visando à construção de resorts, estradas e toda a infraestrutura necessária. A biodiversidade também é capitalizada quando gran- 
des indústrias farmacêuticas utilizam os saberes dos povos tradicionais, bem como a fauna abundante enquanto matéria-prima, para alimentar este setor que não para de crescer. Entretanto, grande parte desta população vê o seu saber e as plantas que tradicionalmente lhe serviram serem patenteados e/ ou contrabandeados para os países-sede dessas empresas.

Esta expropriação da biodiversidade dos países periféricos, transformada em propriedade privada garantidora da lógica do valor, não passa de uma reatualização ${ }^{1}$ do saque e da pilhagem realizada pelos países europeus no Novo Continente. Desta forma, continuam então a capitalizar mediante a expropriação dos recursos naturais e ecológicos da periferia através da lógica expansionista.

Fontes (2010) vai além e demonstra que a expropriação da natureza está diretamente relacionada com a dominação da própria vida humana, relegando-a a uma posição de menor valor frente aos interesses do capital. Influenciando, inclusive, o processo saúde-doença que atualmente encontra-se subjugado à lógica do lucro.

a própria vida biológica humana é expropriada, passando a constituir propriedade privada. Apresentá-lo como mera 'mercantilização' oculta o processo social de expropriação que o constitui. Como se pode ver a seguir, trata-se de uma transformação veloz e que envolve retirar da humanidade o domínio de sua própria natureza. [...] Menos do que enfrentar os grandes problemas de saúde coletiva e pública, derivados estreitamente da lógica social imposta pelo capital, tais expropriações seguem a linha já predominante da produção de 'remédios-mercadorias' para doenças e/ou sofrimentos forjados também pela dinâmica da vida social imposta pelo capital, enveredando ainda mais decididamente na hierarquização do acesso a produtos e técnicas destinados aos segmentos sociais potencialmente capazes de consumi-los, como cosméticos, medicamentos para deter o envelhecimento ou para doenças que acometem mais frequentemente setores mais abastados da população. Porém, o precedente envolve elementos muitos mais dramáticos do que simplesmente o lucro e a desigualdade: o controle privado das condições da existência biológica, expropriadas da população, pode reverter na própria produção de novas e trágicas enfermidades ou necessidades de 'saúde', derivadas do imperativo do lucro ao qual estão submetidos tais controladores de patentes. (FONTES, 2010, p. 61; 62).

O capital procura uma sustentação ideológica que the proporcione um contínuo crescimento e dominação sobre a classe trabalhadora, alijada do direito de ter um território livre de poluição, de continuar a usufruir da biodiversidade de sua região, extraindo dela o seu sustento, suas ervas medicinais e preservando sua cultura e natureza.

${ }^{1}$ Ver Foster e Clark (2006). 
Com a degradação do ecossistema vem também a degeneração das condições de vida de grande parte da população, principalmente nos países periféricos, para onde as grandes indústrias poluidoras têm se voltado. A leitura de Marx (2010, p. 140) sobre o início do capitalismo parece ser um retrato do que tem acontecido atualmente:

Até a necessidade de ar puro deixa de ser uma necessidade para o trabalhador. O homem volta mas uma vez a viver numa caverna, mas agora a caverna está poluída pelo hálito mefítico e pestilento da civilização. Além disso, o trabalhador não tem mais que um direito precário de viver nela, pois ela é para ele um poder estranho que pode ser retirado diariamente e de onde, caso deixasse de pagar, ele poderia ser despejado a qualquer momento. Ele na verdade precisa pagar por este mortuário. Deixa de existir para o trabalhador uma habitação na luz, que Prometeu descreve em Ésquilo como um dos grandes dons pelos quais ele transformou os selvagens em homens. Luz, ar etc. a simples limpeza animal - deixam de ser uma necessidade para o homem. A sujeira - esta poluição e putrefação do homem, o esgoto (esta palavra deve ser entendida no seu sentido literal) da civilização - torna-se um elemento de vida para ele. O descaso universal não-natural, a natureza putrefata, torna-se um elemento de vida para ele. (grifo no original).

A alienação da natureza imposta aos trabalhadores está mais ativa do que nunca. A luz, o ar e a água não fazem mais parte dos seus direitos básicos; ao contrário, os trabalhadores "precisam" se acostumar ao alto preço do desenvolvimento de que eles não usufruem, embora seja deles a conta.

\section{O "problema" natureza sob a ótica marxiana}

Foster (2005) acredita que a ideia de sustentabilidade possa ser encontrada em Marx a partir de sua discussão sobre a agricultura capitalista e as análises sobre a falha metabólica. Para o autor, Marx não acredita em uma saída pautada na sustentabilidade, no capitalismo. Segundo o autor,

A ênfase de Marx na necessidade de manter a terra em benefício da 'cadeia de gerações humanas' (uma idéia que ele havia encontrado no começo da década de 1840 em O que é propriedade?, de Proudhon) captava a verdadeira essência da noção atual de desenvolvimento sustentável, celebremente definida pela Comissão Brundtland como o 'desenvolvimento que satisfaz as necessidades do presente sem comprometer a capacidade das gerações futuras de satisfazer as suas necessidades'. (FOSTER, 2005, p. 230).

Este trecho evidencia a preocupação de Marx com as gerações vindouras e a necessidade de alterar o relacionamento dos homens com a 
natureza, a partir de uma relação sob outras bases que não a capitalista. Por isso, Marx acredita que a sustentabilidade só pode ocorrer em uma sociedade cujos produtores sejam associados. Foster (2005) salienta que esta concepção de "produtores associados" foi pela primeira vez encontrada nos Manuscritos econômico-filosóficos, uma vez que, ao criticar a propriedade privada da terra, Marx aponta para o comunismo enquanto a única saída para o problema. A divisão igualitária da terra proporcionaria a igualdade da mesma forma que a produção associada restauraria "os vínculos íntimos do homem com a terra de modo racional, não mais mediados pela servidão, pela instituição do senhorio [...]." (FOSTER, 2005, p. 115). Subvertendo, desta forma, a ordem da propriedade privada, a terra deixaria de ser apenas um bem, passando a ser de acesso livre a todos os trabalhadores também livres da exploração. Deste modo, teríamos uma natureza e um homem livres da expropriação de outros homens, e somente assim ocorreria novamente a relação metabólica entre o homem e a natureza.

A liberdade dos seres e da natureza seria alcançada apenas na sociedade comunista, na qual a alienação produzida pela propriedade privada e pela acumulação de riqueza seria, definitivamente, extinta. Só assim estariam resolvidas as contradições internas da sociedade, que poderia experienciar uma realidade alterada pela consciência do trabalhador livre, que teria a preocupação com a preservação da natureza. Esta seria liberta do tormento da depredação ocasionada pela poluição, da destruição dos ecossistemas, entre outros males. Só assim se poderia chegar a uma "essência da unidade aperfeiçoada do homem com a natureza, a verdadeira ressurreição da natureza, o naturalismo realizado do homem e o humanismo realizado da natureza." (FOSTER, 2005, p. 116).

\section{Considerações finais}

Em suma, são várias as transformações em andamento que devem ser analisadas à luz de uma concepção teórico-metodológica que dê conta delas, conseguindo ultrapassar aquela visão de mundo imposta por um sistema produtivo alienante.

Marx conseguiu, com seu profundo estudo sobre esta sociedade, descortinar as transformações processadas em seu tempo, bem como alguns pesquisadores citados neste artigo que, apoiados nesta concepção, puderam analisar a temática ambiental sem deixar de lado a emancipação da classe trabalhadora e a produção de uma nova sociabilidade não apartada da natureza.

É evidente que Marx se deteve no estudo sobre o homem e não sobre a natureza. Seu objeto de estudo foi a análise deste modo de produção vigente e os impactos na classe trabalhadora; porém, seu método conseguiu 


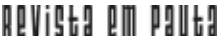

\} A RELAÇÃO NATUREZA-SOCIEDADE NO MODO DE PRODUÇÃO CAPITALISTA - SOUZA, F. A. C. \}

ir além do objeto de estudo em si, captando os estragos da produção capitalista tanto sobre o homem quanto sobre a natureza. O ponto fulcral dessa análise reside no vínculo do homem com a natureza, sendo este um vínculo dialético, reforçado através do trabalho. A continuidade da espécie humana só é possível porque o homem satisfaz-se por meio da criação de objetos que suprem suas necessidades.

Quando há uma interrupção nessa relação, evidencia-se a falha metabólica entre o homem e a natureza. Ou seja, quando o homem é impedido de atuar livremente na natureza através do seu trabalho, devido à apropriação privada do solo e dos meios de produção, o metabolismo entre o homem e a natureza fica interrompido, o que é extremamente prejudicial aos seres humanos. Quando as relações sociais engendraram a proletarização de um grande contingente da população, minando a sua capacidade criadora e relegando-a a uma posição de submissão na produção e na sociedade, estava assim nascendo a alienação do homem, impossibilitado de encontrar no trabalho seu conteúdo libertador.

Já a natureza torna-se mercantilizada e, consequentemente, ressignificada, nos tempos atuais, passando a fazer parte do discurso empresarial e do Estado, a partir do desenvolvimento sustentável. Este começa a propagar a possível junção entre eficiência econômica e ambiental, levada a cabo pelas grandes corporações capitalistas. Esta noção de desenvolvimento sustentável, pautada na sinergia entre sociedade e produção capitalista, para salvaguardar o planeta ajuda a escamotear as verdadeiras intenções que se escondem por trás das grandes corporações. Ficou suficientemente claro, ao longo deste artigo, o que realmente acontece quando a natureza se torna propriedade privada do capital.

A crítica dos autores estudados permite-nos perceber que a proposta da ONU acerca da sustentabilidade é ineficaz, pois não rompe com a racionalidade vigente, limitando-se a propostas de moderação na utilização dos recursos da natureza. Isto leva a uma legitimação da expropriação na medida em que a natureza estará melhor protegida, segundo essa ótica, se for transferida aos domínios capitalistas, transformando-a em valores de troca. Torna-se claro, portanto, que a racionalidade do lucro perpassa toda essa discussão e que é inviável à natureza perpetuar-se sob os auspícios do capital.

Reafirmo que nenhuma saída que não esteja calcada no protagonismo da classe trabalhadora tem chances reais de alteração da ordem vigente, haja visto que só em uma sociedade livre, cuja produção não seja privada, é que poderá surgir um relacionamento dos homens com a natureza sob outras bases. 


\section{Referências}

ASSIS, W. F. T. "In-visibilizar" populações e legitimar iniqüidades. A apropriação do discurso do desenvolvimento sustentável na publicidade do setor elétrico. In: ZHOURI, A. (org.). As tensões do lugar: hidrelétricas, sujeitos e licenciamento ambiental. Belo Horizonte: Editora UFMG. 2011.

FONTES, V. O Brasil e o capital imperialismo. Teoria e história. Rio de Janeiro: UFRJ. 2010.

FOSTER, J. B. A ecologia de Marx: materialismo e natureza. Rio de Janeiro: Civilização Brasileira. 2005.

FOSTER, J. B.; CLARK, B. Imperialismo ecológico: a maldição do capitalismo. In: PANITCH, L.; LEYS, C. (org.). Socialist register 2004: o novo desafio imperial. Buenos Aires: Clacso. 2006.

LEFEBVRE, H. A re-produção das relações de produção. Porto: Edições Escorpião. 1973.

. A sociologia de Marx. Rio de Janeiro: Forense Universitária. 1979. . A revolução urbana. Belo Horizonte: UFMG. 2002

LEFF, E. Racionalidade ambiental: a reapropriação social da natureza. Rio de Janeiro: Civlização Brasileira. 2006.

LIMONAD, E. Questões ambientais contemporâneas, uma contribuição ao debate. In: ENCONTRO NACIONAL DA ASSOCIAÇÃO NACIONAL DE PESQUISA E PÓS-GRADUAÇÃO EM AMBIENTE E SOCIEDADE, 2, São Paulo. Anais... Campinas: ANPPAS. 2004.

MARX, K. O capital. São Paulo: Nova Cultural. 1996.

. Manuscritos econômicos filosóficos. São Paulo: Boitempo. 2010.

. O capital: crítica da economia política. Rio de Janeiro: Civilização Brasileira. 2011.

ONU. A ONU e o Meio Ambiente. 2013. Disponível em: < http://nacoesuni das.org/acao/meio-ambiente/>. Acesso em: 24 de maio de 2013.

Recebido em 29 de abril de 2015

Aprovado para publicação em 28 de junho de 2015. 